\title{
PRODUCTIVITY AND EFFICIENCY DIFFERENCES BETWEEN CZECH AND SLOVAK MILK PRODUCERS
}

\author{
Lukas CECHURA ${ }^{1 *}$, Heinrich HOCKMANN ${ }^{2}$, Zdenka MALA ${ }^{1}$, Michal MALY ${ }^{1}$
}

\author{
Address: \\ ${ }^{1}$ Czech University of Life Sciences Prague, Faculty of Economics and Management, Department of Economics, Kamycka 129, Prague, Czech \\ Republic \\ ${ }^{2}$ IAMO, Agricultural Markets, Marketing and World Agricultural Trade, Theodor-Lieser-Str.2, Halle, Germany \\ *Corresponding author: e-mail: cechura@pef.czu.cz
}

\section{ABSTRACT}

The paper deals with the analysis of productivity and efficiency differences between Czech and Slovak milk producers. The estimate of stochastic metafrontier multiple output distance function revealed that both Czech and Slovak milk producers highly exploit their production possibilities. On the other hand, productivity differences were pronounced. The Slovak regions were found being falling behind. Only the West Slovak regions can keep pace with competitors. The Central Bohemia and Moravian-Silesian regions are the most productive regions. We found that technical efficiency and management component are the most important factors determining the regional differences.

Keywords: milk production, productivity, efficiency, metafrontier analysis, SFA

JEL: D24, O12, P27

\section{INTRODUCTION}

Productivity and efficiency as important indicators of the competitiveness have got a prominent attention of agricultural research in last two decades. The Czech and Slovak agriculture were not exceptions. The authors addressed questions especially related to the EU enlargement and CAP or to the specific factors determining technical efficiency and total factor productivity (e.g. Machek (2013), Machek and Špička (2013), Čechura (2012), Curtiss and Jelínek (2012), Bielik and Hupková (2011), Malá (2011), Sojková, Kropková and Kováč (2008), Latruffe et al. (2008), Davidová et al. (2003)). The authors predominantly oriented on one country, either the Czech Republic or Slovakia, and if the comparison among countries were carried out, it was based on the country specific model estimate. The reliable comparison among the countries is missing.

This paper complements the research on productivity and efficiency by the metafrontier analysis of Czech and Slovak milk production. In particularly, the paper addresses two research questions. The first questions relates to the technical efficiency. The aim is to assess whether there are significant differences in efficiency of input use. The second questions concerns total factor productivity. The aim is to evaluate regional differences in productivity and their sources. In particularly, we will analyse if there is an indication of falling behind or catching up processes on the regional level.

The paper is organized as follows: Chapter Material and Methods contains the theoretical framework, presents the estimation strategy and describes the data set; Chapter Results and Discussion presents results of stochastic metafrontier multiple output distance function estimate, discusses estimated technology and technological change and compares technical efficiency and total factor productivity. Chapter Conclusions contains concluding remarks.

\section{MATERIAL AND METHODS}

\section{Theoretical framework}

The research questions will be addressed by the estimation of multiple output distance function. First, the stochastic frontier multiple output distance function for each country will be estimated. These estimates will serve for the calculation of efficient outputs which we use for the estimation of stochastic metafrontier multiple output distance function. The metafrontier analysis provides unbiased comparison of the efficiency and productivity level of Czech and Slovak milk producers.

We assume that the production possibilities can be well approximated by the translog multiple output distance function. We use a translog functional form since it is flexible and provides well approximation of the production process. Moreover, it permits the imposition of homogeneity (Coelli and Perelman, 1996). The translog output distance function for 3 outputs and 5 inputs, as it is the case in our empirical application, is:

$$
\begin{aligned}
& D_{\text {Oit }}= \\
& \alpha_{0}+\sum_{m=1}^{3} \alpha_{m} \ln y_{m i t}+ \\
& \frac{1}{2} \sum_{m=1}^{3} \sum_{n=1}^{3} \alpha_{m n} \ln y_{m i t} \ln y_{n i t}+\sum_{k=1}^{5} \beta_{k} \ln x_{k i t}+
\end{aligned}
$$


positively linearly homogenous and convex in outputs, as well as decreasing and quasi convex in inputs. Both monotonicity requirements as well as requirements on convexity in outputs and quasi convexity in inputs are met, evaluated on the sample mean.

Since all variables are normalised in logarithm by their sample mean, the first-order parameters of outputs represent the shares of outputs $\mathrm{y}_{2}$ and $\mathrm{y}_{3}$ in the total output and parameters of inputs can be interpreted as elasticities of production on the sample mean. That is, the share of other animal production is about $6 \%$ and the share of plant production is $32 \%$. This holds on the sample mean. As was expected the highest elasticity of production is for material inputs. Labour and land have a considerable effect on the production as well. On the other hand, capital elasticity is lower than expected. This suggests that the milk producers might have faced capital market imperfections.

Since the sum of production elasticities is -0.9516 slightly decreasing returns to scale were estimated.
However, since the sum is closed to one the impact of scale efficiency on a productivity change will not be large on the average. The decreasing returns to scale are more pronounced in Slovakia (-0.9254) as compared to the Czech Republic (-0.9571). Moreover, the impact might be large for individual milk producers since the returns to scale differ significantly in the sample.

The parameters on unobservable management are highly significant except for labour and other material inputs which suggest that the chosen specification well approximates the estimated relationship and that heterogeneity among producers is an important characteristic of farmers with milk specialisation in the Czech Republic and Slovakia. The unobservable management contributes positively to the production and the impact accelerates over time. The increase in management has a positive impact on production elasticities of specific material inputs and negative on land and capital. The impact of technological change on technical efficiency is negative.

Table 2: Parameter estimate

\begin{tabular}{|c|c|c|c|c|c|c|c|}
\hline \multicolumn{4}{|c|}{ Means for random parameters } & \multicolumn{4}{|c|}{ Coefficient on unobservable fixed management } \\
\hline Variable & Coef. & $\overline{\mathrm{SE}}$ & $\mathrm{P}\left[|\mathrm{z}|>\mathrm{Z}^{*}\right]$ & Variable & Coef. & SE & $\mathrm{P}\left[|\mathrm{z}|>\mathrm{Z}^{*}\right]$ \\
\hline Const. & -0.1146 & 0.0043 & 0.0000 & Alpha_m & -0.2692 & 0.0024 & 0.0000 \\
\hline Time & -0.0284 & 0.0007 & 0.0000 & Time & -0.0056 & 0.0010 & 0.0000 \\
\hline $\mathrm{X} 1$ & -0.2073 & 0.0047 & 0.0000 & $\mathrm{X} 1$ & 0.0083 & 0.0056 & 0.1365 \\
\hline $\mathrm{X} 2$ & -0.2437 & 0.0057 & 0.0000 & $\mathrm{X} 2$ & -0.0749 & 0.0070 & 0.0000 \\
\hline X3 & -0.0247 & 0.0029 & 0.0000 & X3 & -0.0073 & 0.0033 & 0.0259 \\
\hline $\mathrm{X} 4$ & -0.2476 & 0.0039 & 0.0000 & $\mathrm{X} 4$ & 0.0653 & 0.0045 & 0.0000 \\
\hline \multirow[t]{2}{*}{$\mathrm{X} 5$} & -0.2283 & 0.0056 & 0.0000 & $\mathrm{X} 5$ & 0.0093 & 0.0071 & 0.1886 \\
\hline & & & & Alpha_mm & -0.0475 & 0.0040 & 0.0000 \\
\hline Variable & Coef. & SE & $\mathrm{P}\left[|\mathrm{z}|>\mathrm{Z}^{*}\right]$ & Variable & Coef. & SE & $\mathrm{P}\left[|\mathrm{z}|>\mathrm{Z}^{*}\right]$ \\
\hline TT & 0.0002 & 0.0008 & 0.7812 & $\mathrm{X} 13$ & -0.0227 & 0.0062 & 0.0003 \\
\hline Y2 & 0.0612 & 0.0023 & 0.0000 & $\mathrm{X} 14$ & 0.0418 & 0.0087 & 0.0000 \\
\hline Y3 & 0.3225 & 0.0025 & 0.0000 & $\mathrm{X} 15$ & 0.0668 & 0.0122 & 0.0000 \\
\hline $\mathrm{Y} 2 \mathrm{~T}$ & -0.0047 & 0.0009 & 0.0000 & $\mathrm{X} 23$ & -0.0038 & 0.0072 & 0.5983 \\
\hline Y3T & 0.0088 & 0.0011 & 0.0000 & $\mathrm{X} 24$ & 0.0958 & 0.0113 & 0.0000 \\
\hline Y22 & 0.0189 & 0.0020 & 0.0000 & $\mathrm{X} 25$ & -0.0148 & 0.0161 & 0.3581 \\
\hline Y33 & 0.1440 & 0.0031 & 0.0000 & X34 & 0.0156 & 0.0046 & 0.0006 \\
\hline Y23 & -0.0062 & 0.0025 & 0.0121 & X35 & 0.0287 & 0.0076 & 0.0002 \\
\hline $\mathrm{X} 1 \mathrm{~T}$ & 0.0009 & 0.0017 & 0.6148 & $\mathrm{X} 45$ & -0.0145 & 0.0101 & 0.1540 \\
\hline $\mathrm{X} 2 \mathrm{~T}$ & 0.0025 & 0.0027 & 0.3569 & Y2X1 & -0.0186 & 0.0056 & 0.0008 \\
\hline X3T & -0.0052 & 0.0014 & 0.0002 & Y2X2 & -0.0283 & 0.0058 & 0.0000 \\
\hline $\mathrm{X} 4 \mathrm{~T}$ & 0.0002 & 0.0017 & 0.9005 & Y2X3 & 0.0100 & 0.0033 & 0.0025 \\
\hline X5T & -0.0004 & 0.0026 & 0.8754 & Y2X4 & 0.0167 & 0.0041 & 0.0000 \\
\hline $\mathrm{X} 11$ & -0.1118 & 0.0082 & 0.0000 & Y2X5 & 0.0134 & 0.0060 & 0.0249 \\
\hline $\mathrm{X} 22$ & -0.0389 & 0.0209 & 0.0624 & Y3X1 & -0.0119 & 0.0054 & 0.0261 \\
\hline X33 & -0.0148 & 0.0049 & 0.0025 & Y3X2 & -0.0202 & 0.0058 & 0.0005 \\
\hline $\mathrm{X} 44$ & -0.1194 & 0.0045 & 0.0000 & Y3X3 & -0.0366 & 0.0031 & 0.0000 \\
\hline X55 & -0.0884 & 0.0209 & 0.0000 & Y3X4 & 0.0147 & 0.0041 & 0.0003 \\
\hline $\mathrm{X} 12$ & 0.0085 & 0.0126 & 0.5009 & Y3X5 & -0.0074 & 0.0058 & 0.2027 \\
\hline Sigma & 0.1157 & 0.0020 & 0.0000 & & & & \\
\hline Lambda & 1.4372 & 0.0877 & 0.0000 & & & & \\
\hline
\end{tabular}

Source: own calculations 
Technological change has a significant positive contribution $\left(\beta_{T}<0\right)$ to the production and the impact does not change over time ( $\beta_{\Pi}$ is not significant). The biased technological change is pronounced only for capital. The technological change is capital using. This direction of the technological change corresponds to our expectations. The adoption of innovations leads to the situation where capital becomes more abundant. Moreover, the direction of biased technological change does not support the above stated implication that the milk producers face the capital market imperfections. Instead of that, the low capital elasticity and direction of biased technical change suggest that the producers have the access to the financial resources (subsidies can play an important role) and become less undercapitalized

Parameter $\lambda$ is highly significant and higher than one. That is the variation in $u_{\mathrm{it}}$ is more pronounced than the variation in the random component $v_{\mathrm{it}}$. The estimates indicate that efficiency differences among milk producers are important reasons for variation in production. However, the estimate did not reveal significant differences among countries not even among regions. The results show that milk producers in the Czech Republic and Slovakia highly exploit their production possibilities (evaluated on the sample mean). The averages of technical efficiency calculated on regional level (NUTSII) are in the interval 0.92 and 0.94.

On the contrary to the technical efficiency TFP differences among countries as well as among regions are significantly pronounced. Table 3 provides the figures on TFP (calculated as a Tornqvist-Theil index /TTI/) and its components - technical change, scale efficiency, technical efficiency and management. Figure 1 provides the graphical illustration of regional TFP differences. The estimate revealed significant regional differences. The highest productivity is in Central Bohemia (CZ02) and Moravian-Silesian region (CZ06 and CZ08). On the other hand, Bratislava region (SK01) and East Slovak regions (SK03 and SK04) have the lowest productivity. The results suggest that Slovak regions are falling behind in milk production. Only the West Slovak region (SK02) can keep a pace with competitors. However, the productivity is on the same level as the worst performing regions in the Czech Republic.

Figure 1: Regional TFP

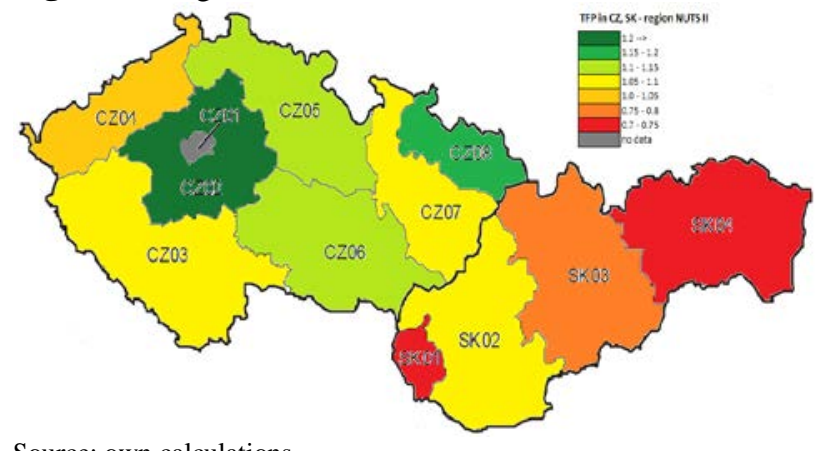

Source: own calculations

Table 3 indicates that technical change and management are the most important determinants of TFP.
The scale and technical efficiency effects are less pronounced. The huge differences among Czech and Slovak regions are due to the management component. Since the management variable can be associated with inputs quality and suitability of regions for milk production. We can conclude that these factors are the most important reasons determining the productivity differences among Czech and Slovak regions.

Table 3: Total factor productivity

\begin{tabular}{|c|c|c|c|c|c|c|}
\hline \multirow{2}{*}{ Country } & \multirow{2}{*}{ NUTSII } & \multirow{2}{*}{ TFP } & \multicolumn{4}{|c|}{ Components of TFP: } \\
\hline & & & $\mathrm{TCH}$ & SE & $\mathrm{TE}$ & MAN \\
\hline \multirow{9}{*}{ 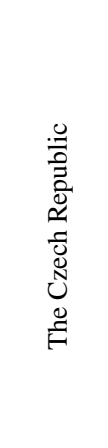 } & CZ02 & 1.2065 & 1.0449 & 0.9939 & 1.0018 & 1.1638 \\
\hline & CZ03 & 1.0535 & 1.0026 & 1.0013 & 0.9988 & 1.0481 \\
\hline & CZ04 & 1.0260 & 0.9651 & 0.9881 & 0.9992 & 1.0751 \\
\hline & CZ05 & 1.1001 & 0.9809 & 1.0205 & 1.0040 & 1.1034 \\
\hline & CZ06 & 1.1406 & 1.0033 & 0.9926 & 0.9968 & 1.1416 \\
\hline & CZ07 & 1.0881 & 0.9811 & 0.9980 & 0.9966 & 1.1075 \\
\hline & CZ08 & 1.1535 & 1.0155 & 1.0056 & 1.0009 & 1.1307 \\
\hline & SK01 & 0.7382 & 0.9837 & 0.9900 & 1.0062 & 0.7627 \\
\hline & SK02 & 1.0558 & 1.0794 & 0.9832 & 0.9985 & 0.9933 \\
\hline \multirow{2}{*}{$\begin{array}{l}\frac{\pi}{\frac{\pi}{2}} \\
\frac{\pi}{\pi} \\
\frac{\partial}{\omega}\end{array}$} & SK03 & 0.7922 & 0.9815 & 0.9934 & 1.0011 & 0.8133 \\
\hline & SK04 & 0.7281 & 0.9861 & 0.9955 & 1.0008 & 0.7423 \\
\hline
\end{tabular}

\section{CONCLUSIONS}

In this section we will concentrate on the questions raised in the introduction, namely the ones regarding technical efficiency and productivity differences between the Czech Republic and Slovakia.

As far as the technical efficiency is concerned no significant differences between the Czech Republic and Slovakia were revealed by the estimate. On average, the milk producers highly exploit their production possibilities.

On the other hand, productivity differences were highly pronounced. The results suggest that Slovak regions are falling behind in milk production. Only the West Slovak region (SK02) can keep a pace with competitors. Technical change and management component were found being the most important factors determining the productivity differences among the Czech and Slovak regions.

Acknowledgments: This paper was created within the project COMPETE - "International comparisons of product supply chains in the agro-food sectors: determinants of their competitiveness and performance on EU and international markets”. The project has received funding from the European Union's Seventh Framework Programme for research, technological development and demonstration under grant agreement no 312029 (www.compete-project.eu). 


\section{REFERENCES}

ÁlVAREZ, A. - ARIAS, C. - GREENE, W. (2003): Fixed Management and time invariant technical efficiency in a random coefficient model. Working Paper, Department of Economics, Stern School of Business, New York University, p. 10.

ÁlVAREZ, A. - ARIAS, C. - GREENE, W. (2004): Accounting for unobservables in production models: management and inefficiency. Economic Working Papers at Centro de Estudios Andaluces E2004/72, Centro de Estudios Andaluces, p. 18. URL: < http://www.eco.uc3m.es/temp/alvarez_pinilla.pdf>

BIELIK, P. - HUPKOVÁ, D. (2011): The Technical Efficiency Analysis - Case of Agricultural Basic Industry in Slovakia. Agris on-line Papers in Economics and Informatics, 3 (1), pages 3-12.

ČECHURA, L. (2012): Technical efficiency and total factor productivity in Czech agriculture. Agriculture Economics - Czech, 58 (4), pages 147-156.

ČECHURA, L. - HOCKMANN, H. (2010): Sources of economical growth in Czech food processing. Prague Economic papers, 2010(2), pages 169-182.

COELLI, T. - PERELMAN, S. (1996): Efficiency Measurment, Multiple-output Technologies and Distance Fucntions: With Application to European Railways, CREPP 96/05, Université de Liége. p. 31.

CURTISS, J. - JELÍNEK, L. (2012): Cost Efficiency and Farm Self-selection in Precision Farming: The Case of Czech Wheat Production. The $131^{\text {th }}$ EAAE Seminar "Innovation for Agricultural Competitiveness and Sustainability of Rural Areas” in Prague, the Czech Republic, September 2012.

DAVIDOVA, S. - GORTON, M. - IRAIZOZ, B. RATINGER, T. (2003): Variations in farm performance in transitional economies: Evidence from the Czech Republic. Journal of Agricultural Economics, 54 (2), pages 227-245. doi: 10.1111/j.1477-9552.2003.tb00061.x
JONDROW, J. - LOVELL, C.A.K. - MATEROV, I.S. SCHMIDT, P.: On the Estimation of Technical Inefficiency in the Stochastic Frontier Production Function Model, Journal of Econometrics, 19, 1982, pp. 233-238. doi: 10.1016/0304-4076(82)90004-5

KUMBHAKAR, S.C. - LOVELL, C.A.K. (2000): Stochastic Frontier Analysis, Cambridge: University Press, p. 333.

LATRUFFE, L. - DAVIDOVÁ, S. - BALCOMBE, K. (2008): Application of a double bootstrap to investigation of determinants of technical efficiency of farms in Central Europe. Working paper 05-03. Institut national de la recherche Agronomique. 25 p.

LOVELL, C.A.K. - RICHARDSON, S. - TRAVERS, P.- WOOD, L.L. (1994): Resources and Functionings: A New View of Inequality in Australia, Models and Measurement of Welfare and Inequality, Berlin, Springer-Verlag.

MACHEK, O. (2013): The Relationship between Financial Performance and Total Factor Productivity: Evidence from the Czech Agricultural Sector. The International Conference on Social Sciences in Izmir (Kusadasi), Turkey, October 2013.

MACHEK, O. - ŠPIČKA, J. (2013): Measuring Performance Growth of Agricultural Sector: A Total Factor Productivity Approach. International Journal of Economics and Statistics, 4 (1), pages 200-208. http://dx.doi.org/10.1155/2014/985149

MALÁ, Z. (2011): Efficiency Analysis of Czech Organic Agriculture. E+M Ekonomie a Management, 14 (1), pages $14-28$.

SOJKOVÁ, Z. - KROPKOVÁ, Z. - KOVÁČ, S. (2008): Comparison of agricultural farm efficiency in Slovak regions before and after EU accession. The $107^{\text {th }} \mathrm{EAAE}$ Seminar "Modelling of Agricultural and Rural Development Policies" in Sevilla, Spain, January 2008. 